\title{
COVID-19 and hereditary spherocytosis: A recipe for hemolysis
}

Tyler S. Severance, ${ }^{1,2,3}$ Mahvish Q. Rahim, ${ }^{1,2,3}$ James French II, ${ }^{1,2,3}$ Richelle M. Baker, ${ }^{1,2,4}$ Andrew Shriner, ${ }^{1,2,4}$ Alka Khaitan, ${ }^{1,2,5}$ Kathleen M. Overholt ${ }^{1,2,3}$

1 Riley Hospital for Children, Indianapolis, Indiana

2 Indiana University School of Medicine, Indianapolis, Indiana

3 Riley Hospital Division of Pediatric Hematology Oncology, Indianapolis, Indiana

4 Riley Hospital Division of Pediatric Hospital Medicine, Indianapolis, Indiana

5 Riley Hospital Division of Pediatric Infectious Disease, Indianapolis, Indiana

To the Editor:

Hereditary spherocytosis (HS) is an inherited hemolytic disease with a wide spectrum of phenotypic expression ranging from asymptomatic to chronic hemolysis.1 Genetic mutations in plasma membrane proteins result in an unstable red blood cell membrane-cytoskeleton interaction resulting in higher risk for hemolysis triggered by stressors including fever, hypoxia, or viral infection.1-3 Splenic clearance of damaged red blood cells results in anemia, thus patients are treated with supportive transfusions or splenectomy in severely affected patients.4, 5

The novel virus, severe acute respiratory syndrome coronavirus 2 (SARS-CoV-2), which causes coronavirus disease 2019 (COVID-19), emerged in Wuhan province in China in December 2019 and has affected over 7 million people globally as of June 2020.6 Many studies have found that the spread of COVID-19 is very rapid due to the highly contagious nature of the disease, resulting in a global pandemic.7-10 While information about this virus is still evolving, there are proportionately fewer pediatric cases requiring hospitalization.11, 12 There is still much to learn regarding how COVID-19 affects children with underlying chronic disorders and what important clinical presentations and labs should be followed in patients with a chronic illness.

We describe a patient infected with COVID-19 in the setting of a known chronic illness, HS, and the resulting presentation and medical complications. This case and discussion is published with maternal consent.

We present a 4-year-old male with a history of moderate HS and sickle cell trait without prior splenectomy who presented with 2 days of cough, congestion, and subjective fevers. He had decreased oral intake and his mother noted yellow discoloration of his eyes. The patient's mother had similar symptoms. There were no known COVID-19 exposures.

This is the author's manuscript of the work published in final edited form as:

Severance, T. S., Rahim, M. Q., French, J., Baker, R. M., Shriner, A., Khaitan, A., \& Overholt, K. M. (2020). COVID-19 and hereditary spherocytosis: A recipe for hemolysis. Pediatric Blood \& Cancer, e28548.

https://doi.org/10.1002/pbc.28548 
He reported to the emergency room and was found to be febrile and tachycardic, but otherwise hemodynamically stable. He had a palpable spleen tip just below the rib margin and noted scleral icterus without other significant findings. Additionally, a chest X-ray was interpreted as normal.

A hematologic work-up was performed and noted in Table 1. The anemia was consistent with an acute hemolytic process. Other cell lines were normal with a reassuring differential, and his metabolic profile was appropriate. Due to the fever, cough, and congestion, a COVID-19 nasopharyngeal polymerase chain reaction was performed. He was admitted and given an infusion of $10 \mathrm{~mL} / \mathrm{kg}$ of packed red blood cells (pRBCs). The transfusion was complicated by a fever, and he subsequently only received $6 \mathrm{~mL} / \mathrm{kg}$ of cells.

On hospital day 1 , labs continued to indicate active hemolysis and hemoglobin was relatively unchanged. His COVID-19 sample returned positive and COVID-19-specific labs were obtained as listed in Table 1. The fever during the transfusion was believed to be due to COVID-19 and not a transfusion reaction. With the persistently low hemoglobin, he received a second transfusion that was well tolerated. His hemoglobin improved, and his hemolysis markers were trending to normal. Hemoglobin obtained $6 \mathrm{~h}$ later was found to be stable, indicating no further hemolysis. He was discharged home with instructions to quarantine for 14 days in accordance with recommended guidelines at the time.

Hereditary spherocytosis results in an increased risk of hemolysis with cellular stress and splenic clearance. Patients and care providers are educated on the importance of monitoring for hemolysis during febrile episodes to avoid an array of complications from acute anemia. While hemolysis in patients with HS and viral infection is a well-known complication, it has only been described in the context of hydroxychloroquine toxicity in subjects with COVID-19.13

Our patient emphasizes the necessity to follow patients at risk for hemolysis closely in the setting of COVID-19. There are reports of patients with sickle cell disease who were infected with COVID-19, however none have addressed the risk in patients with hemoglobin membrinopathies.14-16

There are numerous hemolysis markers that can be followed during a hemolytic crisis. Bilirubin levels can indicate hemolysis as elevation is due to the breakdown of the protoporphyrin IX ring of heme.17 In our patient, it was reassuring to note the downtrending bilirubin value. Ferritin is another hemolytic marker; however, it is also an acute-phase reactant and can be elevated in patients with severe COVID19 infection.17, 18 Lastly, we followed lactate dehydrogenase (LDH) while hospitalized. LDH increases with hemolysis as LDH-1 and LDH-2 are isoenzymes present in red blood cells and released during hemolysis.18 This metric has additional utility in the setting of COVID-19 in that severe infections can progress to a cytokine storm with elevated LDH as one potential marker.

This case highlights the importance of monitoring hemoglobin and hemolytic markers in patients with red cell membrane defects and COVID-19 infection. If widespread COVID-19 testing is initiated, children with positive results and underlying hemolytic disorders should be screened for hemolysis. HS has a varying severity of hemolysis and it is possible that the first hemolytic event could occur in the setting of a COVID-19 infection.

\section{Conflict of Interest}

The authors declare that there is no conflict of interest. 


\section{References}

1. Ciepiela O. Old and new insights into the diagnosis of hereditary sphe-rocytosis. Ann Transl Med. 2018;6(17):339.

2. Bogardus HH, Maksimova YD, Forget BG, Gallagher PG. A de novo band 3 mutation in hereditary spherocytosis. Pediatr Blood Cancer. 2012;58(6):1004.

3. Bogusławska DM, Heger E, Machnicka B, Skulski M, Kuliczkowski K, Sikorski AF. A new frameshift mutation of the $\beta$-spectrin gene asso-ciated with hereditary spherocytosis. Ann Hematol. 2017;96(1):163-165.

4. Schrier SL. What does the spleen see. Blood. 2012;120(2):242-243.

5. Li H, Lu L, Li X, et al. Mechanics of diseased red blood cells in human spleen and consequences for hereditary blood disorders. Proc Natl Acad Sci U S A. 2018;115(38):9574-9579.

6. Dong E, Du H, Gardner L. An interactive web-based dashboard to track COVID-19 in real time. Lancet Infect Dis. 2020;20:533-534.

7. Sanche S, Lin YT, Xu C, Romero-Severson E, Hengartner N, Ke R. High contagiousness and rapid spread of severe acute respiratory syndrome coronavirus 2. Emerg Infect Dis. 2020;26(7). https://doi.org/10.3201/eid2607.200282

8. Li Q, Guan X, Wu P, et al. Early transmission dynamics in Wuhan, China, of novel coronavirusinfected pneumonia. NEnglJMed. 2020;382(13):1199-1207.

9. $\quad$ Sanche S, Lin YT, Xu C, Romero-Severson E, Hengartner N, Ke R. The novel coronavirus, 2019nCoV, is jourhighly contagious and more infectious than initially estimated. medRxiv. 2020. https://doi.org/10. 1101/2020.02.07.20021154

10. ScienceDaily. Coronavirus spreads quickly and sometimes before peo-ple have symptoms, study finds. 2020. https://www.sciencedaily.com/releases/2020/03/200316143313.htm. Accessed April 29, 2020.

11. Dong Y, Mo X, Hu Y, et al. Epidemiology of COVID-19 among children in China. Pediatrics. 2020;145(6):e20200702.

12. Coronavirus disease 2019 in children - United States, February 12-April 2, 2020. MMWR Morb Mortal Wkly Rep. 2020;69:422-426.

13. Tateno Y, Suzuki R, Kitamura Y. Previously undiagnosed hereditary spherocytosis in a patient with jaundice and pyelonephritis: a case report. J Med Case Rep. 2016;10(1):337.

14. De Luna G, Habibi A, Deux JF, et al. Rapid and severe Covid-19 pneu-monia with severe acute chest syndrome in a sickle cell patient suc-cessfully treated with tocilizumab. Am J Hematol. 2020;95:876-878.

15. Beerkens F, John M, Puliafito B, Corbett V, Edwards C, Tremblay D. COVID-19 pneumonia as a cause of acute chest syndrome in an adult sickle cell patient. Am J Hematol. 2020;95:E154-E156. 
16. Nur E, Gaartman AE, van Tuijn CFJ, Tang MW, Biemond BJ. Vaso-occlusive crisis and acute chest syndrome in sickle cell disease due to 2019 novel coronavirus disease (COVID-19). Am J Hematol. 2020;95:725-726.

17. Barcellini W, Fattizzo B. Clinical applications of hemolytic markers in the differential diagnosis and management of hemolytic anemia. Dis Markers. 2015;2015:635670.

18. Mehta $\mathrm{P}, \mathrm{McAuley}$ DF, Brown M, et al. COVID-19: consider cytokine storm syndromes and immunosuppression. Lancet. 2020;395(10229):1033-1034. 
TABLE 1. Clinically relevant labs during hospital stay

\begin{tabular}{|c|c|c|c|c|}
\hline & Hospital day 0 & $\begin{array}{l}\text { Hospital } \\
\text { day } 1\end{array}$ & $\begin{array}{c}\text { Hospital day } 2, \\
5: 52 \text { am }\end{array}$ & $\begin{array}{c}\text { Hospital day } 2, \\
\text { 12:38 pm }\end{array}$ \\
\hline Hemoglobin $(\mathrm{gm} / \mathrm{dL})$ & 6.5 & 6.5 & 10.7 & 10.7 \\
\hline $\begin{array}{l}\text { Absolute reticulocyte } \\
\text { count }\left(\mathrm{K} / \mathrm{mm}^{3}\right)\end{array}$ & 333.2 & 239.9 & 220.3 & - \\
\hline Reticulocyte count (\%) & 14 & 9.4 & 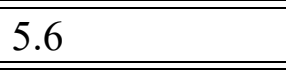 & $\overline{-}$ \\
\hline Total bilirubin $(\mathrm{mg} / \mathrm{dL})$ & & 6.3 & 3.8 & - \\
\hline $\begin{array}{l}\text { Direct bilirubin } \\
(\mathrm{mg} / \mathrm{dL})\end{array}$ & - & 0.8 & - & - \\
\hline LDH (Units/L) & 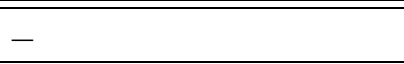 & 661 & 461 & 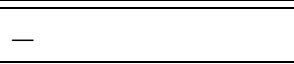 \\
\hline Ferritin (ng/mL) & - & 262 & 415 & - \\
\hline $\mathrm{pRBC}$ transfusion & $\begin{array}{l}\text { Yes, stopped early due } \\
\text { to suspected reaction }\end{array}$ & Yes & No & No \\
\hline
\end{tabular}

- Abbreviations: LDH, lactate dehydrogenase; pRBC, packed red blood cells. 